\title{
Papers
}

\section{Probiotics in prevention of antibiotic associated diarrhoea: meta-analysis}

Aloysius L D'Souza, Chakravarthi Rajkumar, Jonathan Cooke, Christopher J Bulpitt

\begin{abstract}
Objective To evaluate efficacy of probiotics in prevention and treatment of diarrhoea associated with the use of antibiotics.

Design Meta-analysis; outcome data (proportion of patients not getting diarrhoea) were analysed, pooled, and compared to determine odds ratios in treated and control groups.

Identification Studies identified by searching Medline between 1966 and 2000 and the Cochrane Library. Studies reviewed Nine randomised, double blind, placebo controlled trials of probiotics.

Results Two of the nine studies investigated the effects of probiotics in children. Four trials used a yeast (Saccharomyces boulardii), four used lactobacilli, and one used a strain of enterococcus that produced lactic acid. Three trials used a combination of probiotic strains of bacteria. In all nine trials, the probiotics were given in combination with antibiotics and the control groups received placebo and antibiotics. The odds ratio in favour of active treatment over placebo in preventing diarrhoea associated with antibiotics was $0.39(95 \%$ confidence interval 0.25 to $0.62 ; \mathrm{P}<0.001$ ) for the yeast and 0.34 ( 0.19 to $0.61 ; \mathrm{P}<0.01$ for lactobacilli. The combined odds ratio was $0.37(0.26$ to $0.53 ; \mathrm{P}<0.001)$ in favour of active treatment over placebo.

Conclusions The meta-analysis suggests that probiotics can be used to prevent antibiotic associated diarrhoea and that $S$ boulardii and lactobacilli have the potential to be used in this situation. The efficacy of probiotics in treating antibiotic associated diarrhoea remains to be proved. A further large trial in which probiotics are used as preventive agents should look at the costs of and need for routine use of these agents.
\end{abstract}

\section{Introduction}

Biological agents ("biotherapeutic agents" or "probiotics") have been used to treat a variety of infections, most notably infections of mucosal surfaces such as the gut and vagina (box). After the discovery and development of antibiotics, the value of these traditional treatments diminished. Now, however, we are being forced to look at alternatives to antibiotics to combat the ever increasing number of infections that occur because of excessive use of antibiotics.

\section{Probiotics and their uses}

- Probiotics are live organisms that improve the microbial balance of the host

- Probiotics have special properties that make them useful in fighting infections of mucosal surfaces such as the gut and vagina

- Different species of lactobacilli have the potential for use in clinical practice as also the yeast Saccharomyces boulardii

- Probiotics are becoming increasingly available as capsules and dairy based food supplements sold in health food stores and some supermarkets

- The relative lack of side effects makes probiotics a possible way of preventing antibiotic associated diarrhoea

The term "probiotic" was first used to describe "a live microbial supplement, which beneficially affects the host by improving its microbial balance." ${ }^{\prime \prime}$ Since then, research has looked at possible clinical uses for these agents and in 1995, when a greater understanding of their properties had developed, the term "biotherapeutic agents" was proposed to describe micro-organisms with specific therapeutic properties that also inhibit the growth of pathogenic bacteria. ${ }^{2}$

A number of agents have been isolated and studied with a view to clinical use. Streptococcus thermophilus and Lactobacillus bulgaricus, commonly used in the dairy food industry, were among the first to be studied. Other strains that have been used are Bifidobacterium bifidum, B longum, Enterococcus faecium, Saccharomyces boulardii, $L$ acidophilus, $L$ casei, and Lactobacillus GG. However, doctors are still reluctant to use these agents in clinical practice.

In this paper, we review the results from various trials carried out to study their benefits. We also look at the properties of biotherapeutic agents and options for further research.

\section{Materials and methods}

\section{Literature search}

We searched Medline between 1966 to 2000 with the terms "probiotics," "biotherapeutic agents," "lactobacilli," "antibiotic associated diarrhoea," and "Clostridium difficile." We also searched the Cochrane Controlled Trials Register and the Cochrane Database of System-

\section{Editorial by Barbut and Meynard \\ Care of the Elderly Section, Faculty of Medicine, Imperial College School of Medicine, \\ Hammersmith \\ Hospital, London \\ W12 0NN \\ Aloysius L D'Souza research fellow \\ Chakravarthi \\ Rajkumar \\ senior lecturer and \\ honorary consultant \\ Jonathan Cooke \\ statistician \\ Christopher J \\ Bulpitt \\ professor of geriatric \\ medicine \\ Correspondence to: A L D'Souza \\ aloysius.dsouza@ \\ ic.ac.uk}

bmj.com 2002;324:1361 
Table 1 Characteristics of patients in nine trials included in meta-analysis of trials looking at prevention of diarrhoea

\begin{tabular}{|c|c|c|c|c|c|}
\hline \multirow[b]{2}{*}{ Trial } & \multirow{2}{*}{$\begin{array}{c}\text { No of } \\
\text { patients }\end{array}$} & \multirow[b]{2}{*}{ Sex ratio (male:female) } & \multirow[b]{2}{*}{ Route of administration } & \multicolumn{2}{|c|}{ Mean age (years) } \\
\hline & & & & Treatment group & Placebo group \\
\hline$\overline{\text { Adam et } \mathrm{al}^{31}}$ & 388 & $49: 51$ & Oral & 39 & 38 \\
\hline Gotz et al ${ }^{32}$ & 79 & $44: 56$ & Oral & 64 & 65 \\
\hline Surawicz et $\mathrm{al}^{33}$ & 180 & $69: 31$ & Oral or by nasogastric tube & 49 & 45 \\
\hline Wunderlich et al ${ }^{34}$ & 45 & $36: 64$ & Oral & 33 & 33 \\
\hline Tankanow et al ${ }^{35}$ & 38 & $58: 42$ & Oral & 2.4 & 2.4 \\
\hline Orrhage et al ${ }^{36}$ & 20 & $30: 70$ & Oral & 37 & 37 \\
\hline McFarland et $\mathrm{al}^{37}$ & 193 & $65: 35$ & Oral & 41 & 42 \\
\hline Lewis et $\mathrm{a}^{38}$ & 69 & Not provided & Oral & 75 & 77 \\
\hline Vanderhoof et a ${ }^{39}$ & 202 & $45: 55$ & Oral & 4 & 4 \\
\hline
\end{tabular}

atic Reviews. We restricted the search of Medline to published literature that had an English abstract; reviews identified by the searches of Medline and the Cochrane Database gave information about trials without an English abstract. ${ }^{3-6}$ We included all randomised double blind trials that compared the effects of probiotic therapy and placebo (both given in combination with antibiotics). We independently assessed articles and abstracts, and we each put forward articles for inclusion.

Overall, we identified 38 relevant papers on the use of probiotics. We excluded 28 of the 38 papers-three single blind trials, ${ }^{7-9}$ two letters on experimental use of probiotics, ${ }^{10} 11$ three case series, ${ }^{12-14}$ and three trials originally done for another indication. ${ }^{15-17}$ We also excluded five trials that studied only traveller's diarrhoea $^{318-21}$ and 12 trials that studied infectious diarrhoea. ${ }^{4-622-30}$ Of the latter, one trial was in normal subjects exposed to a bacterial challenge, ${ }^{4}$ one in patients infected with $\mathrm{HIV},{ }^{6}$ nine in children with diarrhoea of mixed causes, and one in adults with diarrhoea of mixed causes. ${ }^{26}$ We excluded the trial in HIV patients because the results may not be generalised to other patients. ${ }^{6}$

Ten double blind placebo controlled trials were relevant to our area of interest (nine published in English and one in French). ${ }^{31-40}$ Our meta-analysis included nine that looked at prevention of diarrhoea. We excluded the other trial, which looked at treatment of diarrhoea $^{40}$ : this trial had two arms looking specifically at outcome of treatment-one of recurrent diarrhoea caused by Clostridium difficile and the other of non-recurrent disease caused by this organism.

Meta-analysis and data abstraction

The meta-analysis was carried out according to the recommendations of the QUOROM statement. ${ }^{41}$ The key outcome data taken for analysis included the sample size (table 1), treatment regimens, and numbers of patients in both arms of the study who had an absence of diarrhoea (table 2).

Quantitative data synthesis and validity assessment We used the percentage of patients without diarrhoea in the probiotic and placebo groups as an outcome measure. We defined diarrhoea as "a change from the patient's normal bowel habit, with two or more loose or watery stools for at least two days." We performed three separate analyses: one for the four prevention trials using $S$ boulardii, one for the five trials using lactobacilli or enterococci, and one on pooled data from all nine trials.

We ensured that the odds ratios were not heterogeneous across the trials by performing tests of homogeneity across all nine trials $(\mathrm{P}=0.246)$, across the four yeast trials $(\mathrm{P}=0.065)$, and across the five nonyeast trials $(\mathrm{P}=0.573)$. As these tests did not achieve significance, we combined the information in the tables, using the Mantel Haenszel method. We also calculated summary odds ratios and 95\% confidence intervals for these analyses, and we plotted a graph by using the log of the odds ratios to determine the benefit of treatment over placebo.

\section{Publication bias}

A funnel plot (fig 1$)^{42}$ did not show any publication bias; it showed that the larger studies found benefit and the smaller studies gave results varying from good to no benefit. Two further tests were carried out to investigate possible publication bias-the Begg and Mazumdar adjusted rank correlation test for publication bias and the Egger et al regression asymmetry test for publication bias.

Table 2 Probiotics studied in trials and patients with absence of diarrhoea at end of trial

\begin{tabular}{|c|c|c|c|c|c|c|}
\hline \multirow[b]{2}{*}{ Trial } & \multirow[b]{2}{*}{ Probiotic } & \multirow[b]{2}{*}{ Dose } & \multirow{2}{*}{$\begin{array}{l}\text { Duration of } \\
\text { treatment }\end{array}$} & \multirow[b]{2}{*}{ Antibiotic studied } & \multicolumn{2}{|c|}{$\%$ of patients without diarrhoea } \\
\hline & & & & & Active group & Placebo group \\
\hline Adam et $\mathrm{a}^{31}$ & $S$ boulardii & 4 capsules/day & Variable & Various & 96 & 83 \\
\hline Gotz et a $\left.\right|^{32}$ & $\begin{array}{l}L \text { acidophilus and } \\
L \text { bulgaricus }\end{array}$ & $\begin{array}{l}1 \text { sachet Lactinex four times } \\
\text { a day }\end{array}$ & 5 days & Ampicillin & 100 & 86 \\
\hline Surawicz et al $\left.\right|^{33}$ & $S$ boulardii & $1 \mathrm{~g} /$ day & Variable & Various & 91 & 78 \\
\hline Wunderlich et a ${ }^{34}$ & E faecium SF68 & 1 capsule twice a day & 7 days & Various & 91 & 73 \\
\hline Tankanow et al ${ }^{35}$ & $\begin{array}{l}L \text { acidophilus and } \\
L \text { bulgaricus }\end{array}$ & $1 \mathrm{~g}$ Lactinex four times a day & 10 days & Amoxicillin & 34 & 31 \\
\hline Orrhage et al ${ }^{36}$ & $\begin{array}{l}\text { L acidophilus and } \\
\text { Bifidobacterium longum }\end{array}$ & $\begin{array}{l}\text { Fermented milk with cultures } \\
250 \mathrm{ml} \text { twice a day }\end{array}$ & 21 days & Clindamycin & 80 & 30 \\
\hline McFarland et $\mathrm{al}^{37}$ & $S$ boulardii & $1 \mathrm{~g} / \mathrm{day}$ & 49 days & Various & 93 & 85 \\
\hline Lewis et a ${ }^{38}$ & $S$ boulardii & $113 \mathrm{mg}$ twice a day & 14 days & Various & 79 & 83 \\
\hline Vanderhoof et a ${ }^{39}$ & Lactobacillus GG & $\begin{array}{l}1-2 \text { capsules a day }\left(10^{10}\right. \\
\text { colonies per capsule) }\end{array}$ & 10 days & Various & 93 & 74 \\
\hline
\end{tabular}




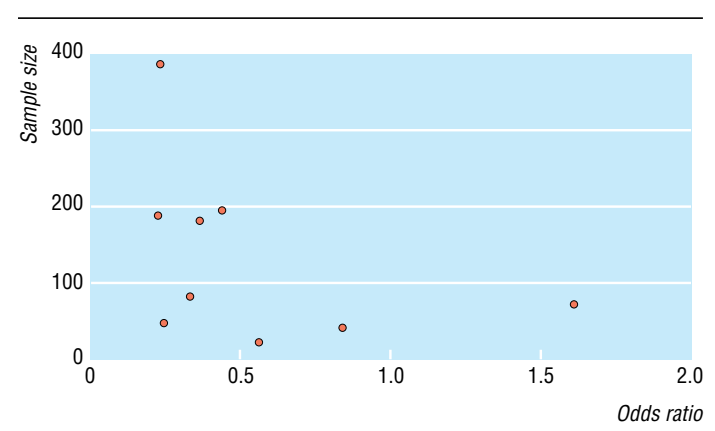

Fig 1 Funnel plot of odds ratio against sample size

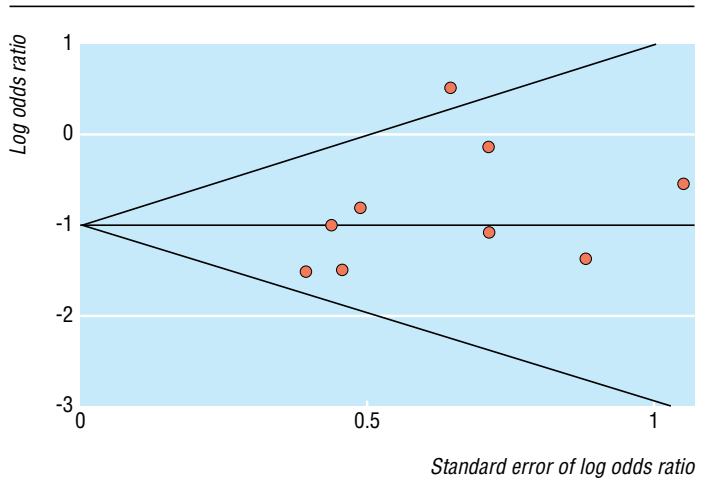

Fig 2 Funnel plot using data from Begg and Mazumdar's adjusted rank correlation test ${ }^{58}$

The Begg and Mazumdar adjusted rank correlation test is a direct statistical analogue of the visual funnel graph (in fig 1). Note that both the test and the funnel graph have low power for detecting publication bias. The Begg and Mazumdar procedure tests for publication bias by determining if there is a significant correlation between the effect estimates and their variances. When this test was used on the data, a P value of 0.297 was obtained.

The Egger et al regression asymmetry test and the regression asymmetry plot tend to suggest publication bias more often than the Begg approach. The Egger test detects funnel plot asymmetry by determining whether the intercept deviates significantly from zero in a regression of the standardised effect estimates against their precision. Egger's test for bias gave a

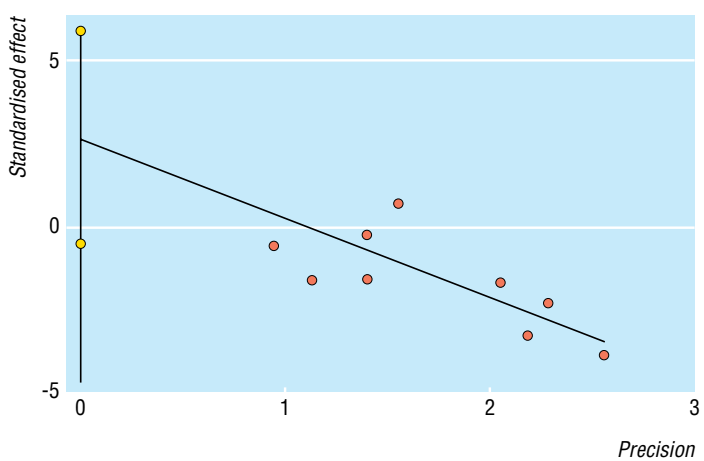

Fig 3 Plot of publication bias using data from Egger et al's regression asymmetry test; $95 \%$ confidence interval is given between markers at $\mathrm{x}=0$
$\mathrm{P}$ value of 0.08 and the confidence interval included zero.

The Begg and Egger tests provide graphical output (figs 2 and 3). In figure 3, the regression asymmetry graph plots the standardised effect estimates (odds ratio) against precision (1 divided by standard error) along with the variance weighted regression line and the confidence interval about the intercept. Failure of this confidence interval to include zero indicates asymmetry in the funnel plot and may give evidence of publication bias. Guide lines at $\mathrm{x}=0$ and $\mathrm{y}=0$ are plotted to help determine visually whether zero is in the confidence interval. As this test did include zero, we concluded that publication bias was not present in our meta-analysis.

\section{Results}

Nine trials were included in the final analysis (fig 4). The study regimens used probiotics combined with one antibiotic or a variety of antibiotics (table 2). All trials studied the efficacy of a probiotic in the prevention of antibiotic associated diarrhoea. The numbers of patients and the duration of follow up varied greatly from study to study, but the patients' characteristics were similar for the active treatment and placebo groups within each study.

We calculated the odds ratio on the basis of the proportion of patients free of diarrhoea on treatment compared with that in control groups. After tests of homogeneity, summary odds ratios and 95\% confidence interval limits were provided for the combined data of the four trials that used $S$ boulardii (yeast trials), the five non-yeast trials, and all nine trials together. The combined odds ratios for the four yeast trials and for the five non-yeast trials were similar $(0.39 \quad(95 \%$ confidence interval 0.25 to 0.62 ) and 0.34 (0.19 to 0.61 ), respectively); both favoured active treatment over placebo in the prevention of antibiotic associated diarrhoea. The odds ratio for pooled data from all nine trials was in favour of active treatment over placebo in the prevention of antibiotic associated diarrhoea ( 0.37 ; 0.26 to 0.53 ). Six studies showed a significant benefit of probiotic treatment compared with placebo $(\mathrm{P}<0.05)$ (fig 5). ${ }^{31} 3334363739$ One study showed benefit for only a subgroup of patients who did not receive nonantibiotic drugs likely to induce diarrhoea, such as magnesium hydroxide (for constipation), lactulose, and bisacodyl (for hepatic encephalopathy). ${ }^{32}$

\section{Findings}

McFarland et al showed that $S$ boulardii lessened diarrhoea associated with antibiotics that contain a $\beta$ lactam ring and prevented recurrent $C$ difficile infection when given in combination with standard antibiotics. ${ }^{37} 40$ There was no benefit, however, when $S$ boulardii was used to treat primary infection with $C$ difficile. ${ }^{40}$

Schellenberg et al reported success with brewer's yeast, $S$ cerevisiae, for the treatment of $C$ difficile colitis. ${ }^{11}$ This finding was criticised in one paper, ${ }^{45}$ but was supported in another. ${ }^{46}$

Lactobacillus GG was successfully used to treat a group of patients with recurrent diarrhoea caused by $C$ difficile. ${ }^{10}$ Vanderhoof et al showed a significant reduction in antibiotic associated diarrhoea, using this agent in children. ${ }^{39}$ The other trials in our meta- 


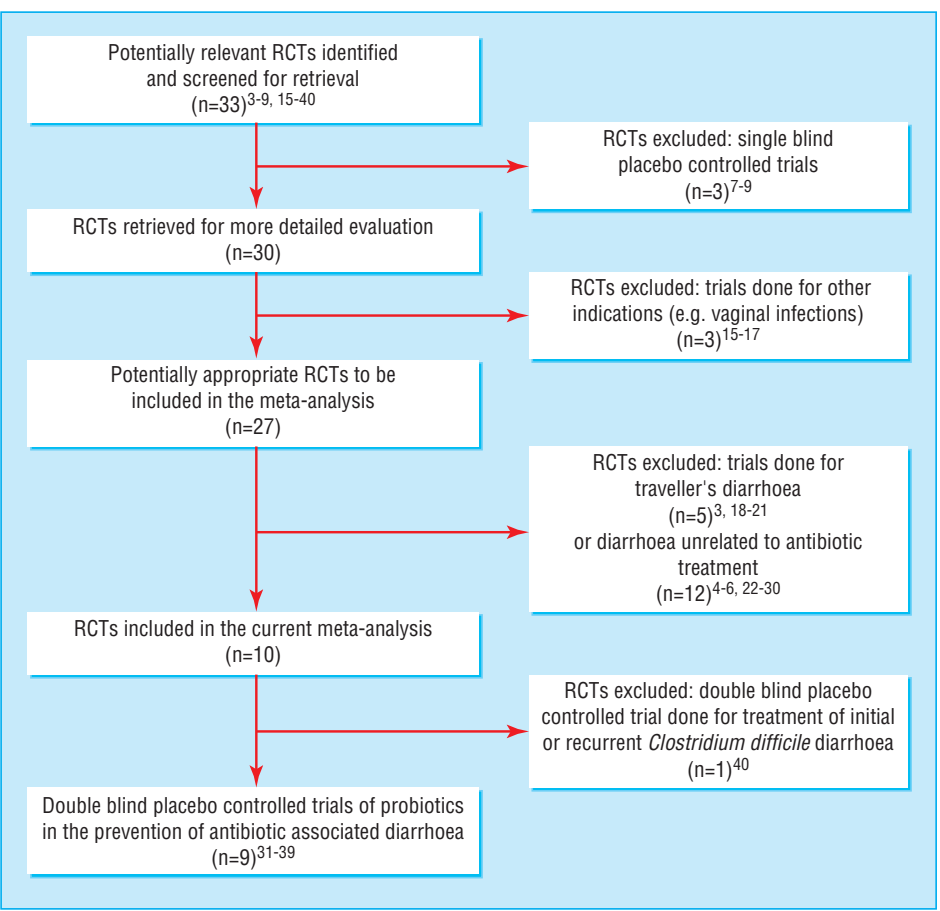

Fig 4 Meta-analysis profile summarising flow trials. RCT=randomised controlled trial

analysis used different strains of lactobacilli, two trials used two different strains of lactobacilli in combination. ${ }^{32}{ }^{35}$ Wunderlich et al showed that the strain of enterococcus strain SF68 that produced lactic acid was useful. $^{34}$ In the Orrhage study, a combination of $L$ acidophilus and Bifidobacterium survived in the human gut and reduced the faecal counts of clostridia. ${ }^{36}$

\section{Discussion}

Our meta-analysis of trials that used live organisms to prevent diarrhoea associated with antibiotics shows that probiotics may be effective in preventing antibiotic associated diarrhoea. We had only a small number of trials in our meta-analysis, and it should be noted that the different antibiotics used in the trials may have altered the risk of patients getting diarrhoea and their response to the probiotics. Although probiotics have been used to prevent or treat diarrhoea of other causes-namely traveller's diarrhoea and infantile

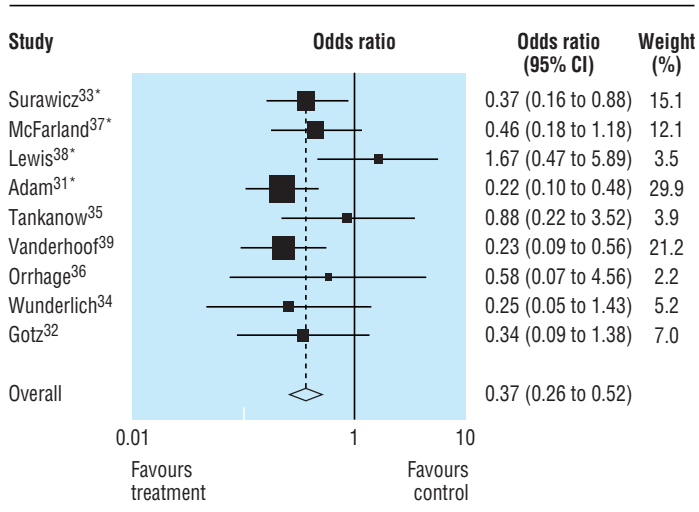

Fig 5 Plot of the log of odds ratios for the proportion of patients free of diarrhoea in treatment groups compared with control groups infectious diarrhoea-we did not include trials that investigated probiotics in these indications; however, most of these studies showed positive results, and some reviews have been encouraging. ${ }^{43}$

The way in which probiotics affect the gut has drawn much interest. To combat the problems of gastrointestinal infection, a probiotic must be nonpathogenic and must act against pathogens by different mechanisms from antibiotics-for example, by competition. More importantly, they should have a fairly rapid onset of action and survive the challenges of gastric acid, bile, or concurrent antibiotics. It is also desirable that they modify immune processes to destroy the invading organism. Saccharomyces boulardii and lactobacilli display these common properties.

A few live organisms have been used in many trials. $S$ boulardii, a non-pathogenic yeast, is one such organism. It has a growth temperature of $37^{\circ} \mathrm{C}$, rapidly colonises the bowel, does not alter the normal gut flora, and is cleared from the colon after treatment is discontinued. ${ }^{44}$ Of the four yeast trials, two studies individually showed significant benefit, ${ }^{31}{ }^{33} 37$ but one did not ${ }^{38}$; differences in the dose and duration of treatment with $S$ boulardii and variations in the period of follow up may explain this disparity. Interestingly, $S$ boulardii can also destroy the receptor site for $C$ difficile toxin A and $\mathrm{B}$ by producing a protease ${ }^{47}$; this could explain how $S$ boulardii was noted to reduce the frequency of toxin B positivity. ${ }^{40}$ This finding was criticised, ${ }^{45}$ but it was also supported. ${ }^{46}$

The other probiotic agent used widely in clinical trials is the Lactobacillus species. The mechanism of action of lactobacilli may be through multiple means: Lactobacillus GG has shown beneficial effects on intestinal immunity, it increases the numbers of cells that secrete immunoglobulin $\mathrm{G}$ and other immunoglobulins in the intestinal mucosa, and it stimulates the local release of interferon. ${ }^{48}$ It also facilitates antigen transport to underlying lymphoid cells, and shows increased uptake in Peyer's patches. ${ }^{48}$ Lactobacillus GG has also been shown to produce an antimicrobial substance that inhibits the growth of Escherichia coli, streptococci, $C$ difficile, Bacteroides fragilis, and Salmonella. ${ }^{49}$ $L$ casei shirota also showed good survival in the gut in separate studies, and mucosal antibody titres (specific to lactobacilli) were increased in the presence of this agent. ${ }^{50}{ }^{51}$ Although there was no discernible change to the numbers of clostridia or enterococci, there was an increase in the numbers of excreted bifidobacteria-a normal bowel anaerobe..$^{51}$ It is possible that this increase in bifidobacteria interferes with the pathogenic potential of $C$ difficile.

Advantages of $S$ boulardii over current clinical practice include its ready availability in the form of brewer's yeast, its easy administration, and the remarkable cost effectiveness of its use compared with vancomycin when infection occurs. ${ }^{11}$ However, there is a risk of fungaemia in immunocompromised patients ${ }^{52}$ and further large trials to document safety are needed before use of this agent will be accepted widely. Some papers report the development of septicaemia in immunocompromised patients and of endocarditis in those with damaged or artificial heart valves who have been treated with lactobacilli ${ }^{53}{ }^{54}$; it would seem prudent to avoid using lactobacilli in such patients. 


\section{What is already known on this topic}

Probiotics are well known for their microbiological properties and have been used to treat gastrointestinal and vaginal mucosal infections

Conflicting results have prevented probiotics from being accepted as viable alternatives to conventional treatments for antibiotic associated diarrhoea

The commercial availability of probiotics is increasing

\section{What this study adds}

Probiotics may prevent antibiotic associated diarrhoea

The potential of specific probiotics to prevent Clostridium difficile infection secondary to the use of antibiotics should be re-examined

A large trial looking at the efficacy of probiotics in preventing antibiotic associated diarrhoea, particularly in elderly patients, with an emphasis on the optimal dose and cost benefits is needed

Probiotics are a possible solution in the prevention of antibiotic associated diarrhoea. Clostridium difficile infection is increasingly prevalent in today's hospital setting, particularly in elderly patients, in whom $10-20 \%$ of such cases occur. $^{55}$ The incidence of antibiotic associated diarrhoea depends on the antibiotic used and each individual patient's risk factors. The standard regimens to treat colitis associated with Clostridium difficile are metronidazole and vancomycin; although these drugs are successful in $80 \%$ of cases, about $20 \%$ of patients suffer from recurrence.$^{56}$ In light of the need to control costs in these days of managed health care, we must re-examine the benefits of using live organisms. Whether the use of probiotics can actually reduce the length of hospital stay by reducing the incidence of infection with $C$ difficile and the need to use antibiotics such as metronidazole and vancomycin are issues that need to be addressed in a clinical trial.

\section{Conclusion}

Our meta-analysis of nine trials shows that biotherapeutic agents may be useful in preventing antibiotic associated diarrhoea, but it provides little support for a role of probiotics in the treatment of such diarrhoea.

The increasing availability, lower costs, and relative lack of side effects of probiotics contrast with the problems associated with current antibiotic regimens. Commercially available strains are being marketed in capsules and yoghurt based drinks, but their potential benefit needs further investigation. It would be wrong to credit the proved benefits of one strain to an untested but closely related strain. ${ }^{57}$ Data from trials have provided us with clear evidence on the efficacy of some strains in the gut, but we still need to see confirmation of their clinical benefit.

Contributors: CJB had the original plan for the metaanalysis, researched individual papers, offered statistical advice, and edited the final paper. AD'S conducted the online and other searches, researched individual papers, extracted output data from individual trials, and wrote the paper. JC was responsible for the statistical analysis, calculated final output data and odds ratios, drew the final graph, and conducted tests of publication bias. CR researched individual papers and assisted in the preparation of the article.

Funding: No funding was sought or obtained for the conduct of this study.

Competing interests: None declared.

1 Fuller RB. Probiotics in human medicine. Gut 1991;32:439-42.

2 McFarland LV, Elmer GW. Biotherapeutic agents: past, present and future. Microecol Ther 1995;23:46-73.

3 Kollaritsch H, Holst H, Grobara P, Wiederman G. Prophylaxe der Reisediarrhöe mit Saccharomyces boulardii. Fortschr Med 1993;111:153-6.

4 Chicoine L, Joncas JH. Emploi des ferments lactiques dans la gastro-entérite non bactérienne. Union Med Canada 1973;102:1114-5.

5 Chapoy P. Traitement des diarrhées aiguës infantiles: essai contrôlé de Saccharomyces boulardii. Ann Pédiatr 1985;32:561-3.

6 Saint-Marc T, Rossello-Prats L, Touraine JL. Efficacité de Saccharomyces boulardii dans le traitement des diarrhées du SIDA. Ann Med Intern 1991;142:64-5.

7 Colombel JF, Cortot A, Neut C, Romond C. Yoghurt with Bifidobacterium longum reduces erythromycin induced gastrointestinal effects. Lancet 1987 ;ii:43.

8 Siitonen S, Vapaatalo H, Salminen S, Gordin A, Saxelin M, Wikberg R, et al. Effect of Lactobacillus GG yoghurt in the prevention of antibioticassociated diarrhoea. Ann Med 1990;22:57-9.

9 Isolauri E, Juntunen M, Rautanen T, Silanaukee P, Koivula T. A human Lactobacillus strain (L casei GG) promotes recovery from acute diarrhoea in children. Pediatrics 1991;88:90-7.

10 Gorbach SL, Chang TW, Goldin B. Successful treatment of relapsing C difficile colitis with Lactobacillus GG. Lancet 1987;ii:1519.

11 Schellenberg D, Bonington A, Champion CM, Lancaster R, Webb S, Main J. Treatment of C difficile diarrhoea with Brewer's yeast. Lance 1994;343:171-2.

12 Buts JP, Corthier G, Delmee M. Saccharomyces boulardii for Clostridium difficile-associated enteropathies in infants. J Pediatr Gastroenterol Nutr 1993:16:419-25.

13 Biller JA, Katz AJ, Flores AF, Buie TM, Gorbach SL. Treatment of recurrent Clostridium difficile colitis with Lactobacillus GG.J Pediatr Gastroenterol Nutr 1995;21:224-7.

14 Levy J. Experience with live Lactobacillus plantarum strain 299v in immune-deficient infants [abstract]. Gastroenterology 1997;112:A397.

15 Borgia M, Sepe N, Brancaro V, Simone P, Borgia R. Effect of lactic acidproducing bacteria Streptococcus SF68 strain on body weight in man: a double-blind controlled study. Current Ther Res 1983;33:214-8.

16 Reid G, Bruce AW, Taylor M. Influence of three day anti-microbial therapy and Lactobacillus vaginal suppositories on recurrence of urinary tract infections. Clin Ther 1992;14:11-6.

17 Bleichner G, Blehaut H, Mentec H, Moyse D. Saccharomyces boulardi prevents diarrhoea in critically ill tube-fed patients. A multi-centre, randomized, double blind, placebo-controlled trial. Intensive Care Med 1997;23:517-23

18 Pozo-Olano JD, Warram JH, Gómez RG, Cavazos MG. Effect of a Lactobacillus preparation on traveller's diarrhoea. Gastroenterology $1978 ; 74: 829-30$

19 Black FT, Anderson PL, Orskov J, Gaarslev K, Laulund S. Prophylactic efficacy of Lactobacilli on traveller's diarrhoea. Travel Med 1989;7:333-5.

20 Oksanen PJ, Salminen S, Saxelin M, Hamalainen P, Ihantola-Vormisto A, Muurasniemi-Isoviita L, et al. Prevention of traveller's diarrhoea by Lactobacillus GG. Ann Med 1990;22:53-6.

21 Katelaris PH, Salam I. Lactobacilli to prevent traveller's diarrhoea. $N$ Engl J Med 1995;333:1360-1.

22 Pearce JL, Hamilton JR. Controlled trial of orally administered Lactobacilli in acute infantile diarrhoea. J Pediatrics 1974;84:261-2.

23 Bellomo G, Mangiagle A, Nicastro L, Frigerio G. A controlled double-blind study of SF68 strain as a new biological preparation for the treatment of diarrhoea in pediatrics. Curr Ther Res 1980;28:927-36.

24 Clements ML, Levine MM, Black RE, Robins-Browne RM, Cisneros LA, Drusano GL, et al. Lactobacillus prophylaxis for diarrhoea due to enterotoxigenic E. coli. Antimicrob Agents Chemother 1981;20:104-8.

25 Tojo M, Oikawa T, Morikawa Y, Yamashita N, Iwata S, Satoh Y, et al. The effects of Bifidobacterium breve administration on campylobacter enteritis. Acta Ped Jap 1987;29:160-7.

26 Mitra AK, Rabbani GH. A double blind controlled trial of Streptococcus SF68 in adults with acute diarrhoea due to Vibrio cholerae and enterotoxigenic E. coli. Gastroenterology 1990;99:1149-52.

27 Guandalini S, Pensabene L, Zikri MA, Dias JA, Casali LG, Hoekstra H, et al. Lactobacillus GG administered in oral rehydration solution to children with acute diarrhoea: a multicenter European trial. J Pediatr Gastroenterol Nutr 2000;30:54-60.

28 Isolauri E, Kaila M, Mykkänen H, Ling WH, Salminen S. Oral bacteriotherapy for viral gastro-enteritis. Dig Dis Sci 1994;39:2595-600.

29 Saavadra JM, Bauman NA, Oung I, Perman JA, Yolken RH. Feeding of Bifidobacterium bifidum and Streptococcus thermophilus to infants in hospital for prevention of diarrhoea and shedding of rotavirus. Lancet 1994;344:1046-9.

30 Oberhelman RA, Gilman RH, Sheen P, Taylor DN, Black RE, Cabrera L, et al. A placebo-controlled trial of Lactobacillus $G G$ to prevent diarrhoea in undernourished Peruvian children. J Pediatrics 1999;134:15-20.

31 Adam J, Barret A, Barret-Bellet C. Essais cliniques contrôlés en double insu de l'ultra-levure lyophilisée: étude multicentrique par 25 médicins de 388 cas. Gaz Med Fr 1977;84:2072-8. 
32 Gotz V, Romankiewicz JA, Moss J, Murray HW. Prophylaxis against ampicillin associated diarrhoea with Lactobacillus preparation. Am J Hosp Pharm 1979;36:754-7.

33 Surawicz CM, Elmer GW, Speelman P, McFarland LV, Chinn J, Van Belle G. Prevention of antibiotic associated diarrhoea by Saccharomyces boulardii. Gastroenterology 1989:96:981-8.

34 Wunderlich PF, Braun L, Fumagalli I, D’Apuzzo V, Heim F, Karly M, et al. Double-blind report on the efficacy of lactic acid-producing Enterococcus SF68 in the prevention of antibiotic-associated diarrhoea and in the treatment of acute diarrhoea. J Int Med Res 1989;17:333-8.

35 Tankanow RM, Ross MB, Ertel IJ, Dickinson DG, McCormick LS, Garfinkel JF. Double blind, placebo-controlled study of the efficacy of Lactinex in the prophylaxis of amoxicillin-induced diarrhoea. DICP, Ann Pharm 1990;24:382-4

36 Orrhage K, Brismar B, Nord CE. Effects of supplements of Bifidobacterium longum and Lactobacillus acidophilus on intestinal microbiota during administration of clindamycin. Microb Ecol Health Dis $1994 ; 7: 17-25$

37 McFarland LV, Surawicz CM, Greenberg RN, Elmer GW, Moyer KA, Melcher SA, et al. Prevention of $\beta$-lactam-associated diarrhoea by Saccharomyces boulardii compared with placebo. Am J Gastroenterol 1995;90:439-48.

38 Lewis SJ, Potts LF, Barry RE. The lack of therapeutic effect of $\mathrm{S}$ boulardii in the prevention of antibiotic related diarrhoea in elderly patients.J Infect 1998;36:171-4.

39 Vanderhoof JA, Whitney DB, Antonson DL, Hanner TL, Lupo JV, Young RJ. Lactobacillus GG in the prevention of antibiotic-associated diarrhoea in children. J Pediatrics 1999;135:564-8.

40 McFarland LV, Surawicz CM, Greenberg RN, Fekety R, Elmer GW, Moyer $\mathrm{KA}$, et al. A randomized placebo-controlled trial of $\mathrm{S}$ boulardii in combination with standard antibiotics for Clostridium difficile disease. JAMA 1994;271:1913-8

41 Moher D, Cook DJ, Eastwood S, Olkin I, Rennie D, Stroup DF, for the QUOROM Group. Improving the quality of reports of meta-analyses of randomised controlled trials: the QUOROM statement. Lancet 1999;354:1896-900.

42 Egger M, Davey-Smith G, Schneider M, Minder CE. Bias in meta-analysis detected by a simple graphical test. BMJ 1997;315:629-34.

43 Elmer GW, Surawicz CM, McFarland LV. Biotherapeutic agents: a neglected modality for treatment and prevention of selected intestinal and vaginal infections. JAMA 1996;275:870-6.

\section{Science commentary: Probiotics}

Abi Berger science editor, BMJ

Probiotics are microbes that protect their host, and in some cases they can prevent disease. They are immunomodulating bacteria that have very low virulence compared with the more pathogenic gut flora such as Escherichia coli and clostridia. Lactobacilli and bifidobacteria are examples of probiotics found in the large intestine.

Lactobacillus GG can prevent diarrhoea and atopy in children. ${ }^{2}$ In the gut, probiotic bacteria are thought to occupy binding sites on the gut mucosa, preventing pathogenic bacteria from adhering to the mucosa. Lactobacilli also produce proteinaceous compoundsbacteriocins - that act as local antibiotics against more pathogenic organisms. But what is known about what happens in vitro cannot necessarily be extrapolated to the complexity of the ecosystem of the human gut.

Diarrhoea associated with antibiotics is presumed to result from the antibiotics disrupting the normal flora in the gut of a healthy person. Such disruptions cause dysfunction of the gut's ecosystem, and they may allow pathogenic bacteria to colonise the gut and gain access to the mucosa. Whether probiotic supplements stop this process by reducing the disruption or by acting as substitutes for the healthy flora is unclear. Probiotics may compete with pathogens for the nutrients the pathogens need to grow, or they may modify toxins produced by pathogens or toxin receptors found in the
44 Blehaut H, Massot J, Elmer GW, Levy RH. Disposition kinetics of S boulardii in man and rat. Biopharm Drug Dispos 1989;10:353-64.

45 McFarland LV. S boulardii is not $\mathrm{S}$ cerevisiae. Clin Infect Dis 1996;22:200-1.

46 McCullough MJ, Clemons KV, McCusker JH, Stevens DA. Species identification and virulence attributes of Saccharomyces boulardii. J Clin Microbiol 1998;36:2613-7.

47 Castagliulo I, Riegler MF, Valenick L, LaMont JT, Pothoulakis C. S. boulardii protease inhibits effects of C. difficile toxins A and B in human colonic mucosa. Infect Immun 1999;67:302-7.

48 Benno Y, He F, Hosada M, Hashimoto H, Kojima T, Yamazaki K, et al Effects of Lactobacillus GG yoghurt on human intestinal micro-ecology in Japanese subjects. Nutr Today 1996;31(6 suppl):9-11S.

49 Gorbach SL. The discovery of Lactobacillus GG. Nutr Today 1996;31(6 suppl):2-4S

50 Spanhaak S, Havenaar R, Schaafsma G. Effect of consumption of milk fermented by Lactobacillus casei shirota on intestinal microflora and immune parameters in humans. Eur J Clin Nutr 1998;52:899-907.

51 Yuki N, Watanabe K, Mike A, Tagami Y, Tanaka R, Ohwaki M, et al. Survival of probiotic Lactobacillus casei shirota in the GI tract-selective isolation using monoclonal antibodies. Int J Food Microbiol 1999;48:51-7.

52 Niault M, Thomas F, Prost J, Ansari FH, Kalfon P. Fungaemia due to Saccharomyces species in a patient treated with enteral S boulardii. Clin Infect Dis 1999;28:930.

53 Harty DWS, Oakey HJ, Knox KW. Pathogenic potential of lactobacilli. Int J Food Microbiol 1994;24:179-89.

54 Schlegel L, Lemerle S, Geslin P. Lactobacillus species as opportunistic pathogens in immune-compromised patients. Eur J Clin Microbiol Infect Dis $1998 ; 17: 887-8$.

55 Kelly CP, Pothoulakis C, Lamont JT. Clostridium difficile colitis. $N$ Engl J Med 1994:330:257-62.

56 Walters BAJ, Roberts R, Stafford R, Seneviratne E. Recurrence of antibiotic-associated colitis: endogenous persistence of $\mathrm{C}$ difficile during vancomycin therapy. Gut 1983;24:206-12.

57 Berg RD. Probiotics, prebiotics or 'conbiotics'. Trends Microbiol 1998;6:8992.

58 Begg CB, Mazumdar M. Operating characteristics of a rank correlation test for publication bias. Biometrics 1994;50:1088-101.

(Accepted 7 November 2001) gut wall, or they may stimulate immune responses to pathogens.

The exact mechanisms by which probiotics prevent atopy are also under debate. ${ }^{3}$ One suggestion is that the establishment and maintenance of innate immune tolerance is mediated by $\mathrm{T}$ helper 1 cells and linked in some way to the faecal flora. If the Th1 response is particularly robust, the allergic response mediated by T helper 2 cells tends not to be so strong. Probiotics may prevent atopy by supporting the faecal flora, strengthening the Th1 response, and reducing the allergic response.

In the countries of continental Europe, probiotics are regarded as medicines, and they are prescribed alongside antibiotics. In other countries, probiotics are marketed as supplements and are sold over the counter-although preparations such as "bioyoghurts" do not always contain probiotic strains proved to be clinically useful.

1 Szajewska H, Mrukowicz JZ. Probiotics in the treatment and prevention of acute infectious diarrhoea in infants and children: a systematic review of published randomised, double blind, placebo-controlled trials. J Pediatr Gastroenterol Nutr 2001;33 (suppl):S17-25.

2 Kalliomaki M, Salminen S, Arvilommi H, Kero P, Koskinen P, Isolauri E. Probiotics in primary prevention of atopic disease: a randomised placebo-controlled trial. Lancet 2001;357:1076-9.

3 Murch S. Toll of allergy reduced by probiotics. Lancet 2001;357:1057-9. 